\title{
SISTEMATIZAÇÃO DE DIRETRIZES PROJETUAIS PARA UMA UNIDADE DE ACOLHIMENTO
}

\author{
HAMES, Caroline
}

Universidade do Estado de Santa Catarina, e-mail: carolinehamess@gmail.com

\begin{abstract}
RESUMO
O presente artigo traz os já existentes parâmetros de infraestrutura das Unidades de Acolhimento para pessoas em situação de rua a fim de colocá-los no campo da discussão para sistematização de critérios de avaliação que, aliados aos estudos de casos, possam gerar diretrizes projetuais a serem correlacionadas aos princípios da humanização no âmbito da arquitetura. A priori, adentra-se na realidade dos moradores de rua, compreende-se suas problemáticas e estuda-se o papel da humanização e da psicologia ambiental nos espaços de saúde. Isto posto, o estudo de caso e a aplicação dos critérios de avaliação objetivam conhecer as normativas e os espaços mínimos exigidos pela legislação, bem como os caminhos traçados pelas pessoas em situação de rua dentro dos centros assistenciais. A partir do tratamento dos dados coletados, desenvolve-se um suporte para o lançamento de diretrizes projetuais para uma Unidade de Acolhimento envolta por princípios da humanização. Os resultados apresentados são oriundos da pesquisa desenvolvida para o trabalho de conclusão de curso.
\end{abstract}

Palavras-chave: Humanização, Psicologia, Arquitetura, Acolhimento.

\begin{abstract}
This article brings the already existing infrastructure parameters of the Reception Units for people in the street situation in order to place them in the discussion field for the systematization of evaluation criteria that, together with the case studies, can generate design guidelines to be correlated with the principles of humanization within the framework of architecture. A priori, it penetrates into the reality of the street dwellers, their problems are understood and the role of humanization and environmental psychology in the health spaces is studied. Therefore, the case study and the application of the evaluation criteria aim to know the regulations and minimum spaces required by the legislation, as well as the paths traced by street people within the care centers. Based on the treatment of the collected data, a support is developed for the launching of design guidelines for a Reception Unit based on principles of humanization. The results presented are from the research developed for the course completion work.
\end{abstract}

Keywords: Humanization, Psychology, Architecture, Reception.

\section{INTRODUÇÃO}

Invisível e estigmatizado, o sujeito do habitar a rua requer ações efetivas que o direcione para a saída da rua, reinsiram-no na sociedade como cidadão garantido de direitos e promovam soluções para a problemática de sua permanência nas Unidades de Acolhimento. Problemática já citada pelo Ministério do Desenvolvimento Social (MDS) em 2009 na Pesquisa Nacional

HAMES, C. Sistematização de diretrizes projetuais para uma Unidade de Acolhimento. In: SIMPÓSIO BRASILEIRO DE QUALIDADE DO PROJETO NO AMBIENTE CONSTRUÍDO, 6., 2019, Uberlândia. Anais... Uberlândia: PPGAU/FAUeD/UFU, 2019. p. 1407-1418. DOI https://doi.org/10.14393/sbqp19126. 
sobre a População em situação de Rua, onde 69,4\% preferem permanecer nas ruas a usar uma instituição assistencial.

Sendo assim, nasce a temática de usar os princípios da humanização e da psicologia ambiental como suporte para elaboração de diretrizes que possam promover um espaço físico de qualidade para a efetivação das ações e dos serviços ofertados pelo Sistema Único de Assistência Social (SUAS). Nesse viés, cabe ressaltar a afirmação de Loschiavo (2005) acerca da escassez de pesquisas acadêmicas direcionadas ao estudo da arquitetura como ferramenta projetual para a concepção de espaços às populações de rua.

Para tal, buscou-se a revisão bibliográfica acerca dos moradores de rua pelo olhos de Esquinca (2013), das normativas da Unidade de Acolhimento pelo Ministério da Saúde, da correlação dos conceitos de arquitetura com a humanização, pela perspectiva de Ciaco (2010) e de Kowaltowski (1989), com a Psicologia Ambiental, por Aragonés e Amérigo (1998) e com o Desenho Universal por Cambiaghi (2007) e por Dischinger; Ely e Piardi (2012), a fim de construir um embasamento teórico e compreender as necessidades desse público.

Dessa forma, a aplicação dos critérios de avaliação gerados a partir da fundamentação teórica e o tratamento dos dados coletados no estudo de caso, caminham a pesquisa para a elaboração de diretrizes que visem atender as exigências das políticas públicas voltadas às pessoas em situação de rua.

\section{FUNDAMENTAÇÃO TEÓRICA}

\subsection{O sujeito do habitar a rua}

A crença de que o fenômeno do habitar a rua seja pertencente aos tempos contemporâneos é errônea, Esquinca (2013) já o associa a uma circunstância oriunda das aglomerações urbanas da Antiguidade.

Em suma, a sucessão de eventos ao longo da história contribuiu para uma segregação política, econômica, social e espacial. O pensamento acelerado da globalização, o avanço tecnológico, a crise econômica dos anos 90 e o rápido crescimento das cidades provocaram mudanças no mundo do trabalho, ampliaram o desemprego e intensificaram as problemáticas das classes subalternas.

Por fim, uma parcela dessa população vulnerabilizada enxergou na rua uma alternativa para sobrevivência. Alternativa esta indigna de um ser humano.

A Política Nacional para População de Rua (PNAS) adota o seguinte conceito para a definição dessa população:

Grupo populacional heterogêneo que possui em comum a pobreza extrema, os vínculos familiares interrompidos ou fragilizados e a inexistência de moradia convencional regular, e que utiliza logradouros públicos e as áreas degradadas como espaço de moradia e de sustento, de forma temporária ou permanente, bem como as Unidade de Acolhimento para pernoite temporário ou como moradia provisória. (Decreto $\mathrm{n}^{\circ}$ 7053/2009, art. 1, Parágrafo Único). 
Essa noção revela a pobreza extrema e a ausência de moradia como pontos comuns entre a diversidade dos moradores de rua e seus diferentes modos de ser e sobreviver.

\subsection{Unidade de Acolhimento}

A complexidade de propor uma Unidade de Acolhimento que consiga alcançar êxito em todas as suas esferas de exigências está relacionada com as múltiplas facetas do habitante de rua e como atender as necessidades inerentes a cada um.

A Política Nacional de Assistência Social (PNAS) estabelece os princípios para implementação do Sistema Único de Assistência Social (SUAS) que reorganiza os serviços de proteção social aos cidadãos, como: garantia da cidadania e dos direitos humanos; geração de renda; saúde; moradia; cultura; acolhimento; projetos de capacitação e alfabetização.

Como materialização do espaço físico para a promoção desses serviços, a Unidade de Acolhimento foi instituída pela portaria GM/MS n.121 de 25 de janeiro de 2012 e se enquadra na classificação de Proteção Social Especial de Alta Complexidade.

Para assegurar o exposto, o Ministério do Desenvolvimento Social e o Ministério da Saúde criam uma cartilha com orientações para a estruturação efetiva desse serviço, indicando os ambientes mínimos (Tabela 1) e as ações (Quadro 1) que estes devem atender.

Tabela 1 - Ambientes mínimos segundo o Ministério da Saúde

\begin{tabular}{|c|c|c|c|}
\hline Ambiente & $\begin{array}{c}\text { Quant. Mín. } \\
\text { Obrigatória }\end{array}$ & $\begin{array}{c}\text { Área Unit. Mín. } \\
\text { (aprox.) obrigatória (m²) }\end{array}$ & $\begin{array}{c}\text { Área } \\
\text { total }\end{array}$ \\
\hline 1. Sala de acolhimento & 1 & 36 & 36 \\
\hline 2. Quarto coletivo & 4 & 18 & 72 \\
\hline 3. Banheiros com chuveiros & 2 & 4,8 & 9,6 \\
\hline 4. Sala Administrativa (Escritório) & 1 & 9 & 9 \\
\hline 5. Sala de TV & 1 & 30 & 30 \\
\hline 6. Almoxarifado & 1 & 3 & 3 \\
\hline 7. Refeitório & 1 & 18 & 18 \\
\hline 8. Cozinha & 1 & 16 & 16 \\
\hline 9. Banheiro para funcionários & 2 & 12 & 24 \\
\hline 10. Lavanderia & 1 & 4 & 7 \\
\hline 11. Abrigo externo para resíduos sólidos & 1 & Área total & $\mathbf{2 2 8 , 6}$ \\
\hline & & Área total + Área de & $\mathbf{2 7 4 , 3 2}$ \\
\hline & & circulação (20\% [área total]) & 24 \\
\hline 12. Área externa de convivência & 1 & 24 & 21 \\
\hline 13. Área externa para embarque & 1 & Área total (interna + externa) & $\mathbf{3 1 9 , 3 2}$ \\
\hline desembarque de ambulância & & &
\end{tabular}

Fonte: BRASIL (2013), adaptada pela autora (2018) 
Quadro 1 - Ações e Recursos necessários nas Unidades de Acolhimento

\begin{tabular}{|c|c|c|c|}
\hline Ações & Recursos Físicos & Recursos Humanos & Recursos Materiais \\
\hline Acolhimento & Banheiro & Assistente social & Armário Individual \\
\hline $\begin{array}{c}\text { Articulação da rede } \\
\text { de serviços }\end{array}$ & Copa/cozinha & Auxiliar administrativo & $\begin{array}{l}\text { Equipamentos de } \\
\text { informática com } \\
\text { internet }\end{array}$ \\
\hline $\begin{array}{l}\text { Atendimento da rede } \\
\text { de serviços } \\
\text { assistenciais }\end{array}$ & Lavanderia & Auxiliar educativo & $\begin{array}{l}\text { Guarda prontuários } \\
\text { físicos }\end{array}$ \\
\hline Cadastro dos usuários & Recepção & $\begin{array}{l}\text { Coordenador em serviço } \\
\text { social ou psicologia }\end{array}$ & $\begin{array}{l}\text { Jogos; atividade } \\
\text { recreativas; } \\
\text { ocupacionais; } \\
\text { terapêuticas }\end{array}$ \\
\hline $\begin{array}{l}\text { Convívio familiar, } \\
\text { grupal e social }\end{array}$ & Refeitório & Cozinheiro & $\begin{array}{c}\text { Lavagem e secagem } \\
\text { de roupas }\end{array}$ \\
\hline $\begin{array}{c}\text { Entrevista } \\
\text { individual/família }\end{array}$ & Sala administrativa & Motorista & Material multimídia \\
\hline $\begin{array}{c}\text { Oficinas e atividades } \\
\text { coletivas }\end{array}$ & $\begin{array}{c}\text { Sala de } \\
\text { atendimento } \\
\text { individualizado }\end{array}$ & $\begin{array}{l}\text { Profissionais especializados } \\
\text { em abordagem social }\end{array}$ & Refeições diárias \\
\hline $\begin{array}{l}\text { Orientação e } \\
\text { atendimento em } \\
\text { grupo }\end{array}$ & $\begin{array}{c}\text { Sala de } \\
\text { coordenação }\end{array}$ & Psicólogo & $\begin{array}{l}\text { Sofás, cadeiras e } \\
\text { bancos para } \\
\text { atendimento }\end{array}$ \\
\hline $\begin{array}{l}\text { Orientação Jurídico- } \\
\text { social }\end{array}$ & Sala de Reunião & Segurança & \multirow{3}{*}{$\begin{array}{c}\text { Veículo para } \\
\text { utilização da equipe }\end{array}$} \\
\hline \multirow[b]{2}{*}{$\begin{array}{l}\text { Programa de } \\
\text { capacitação }\end{array}$} & \multirow[b]{2}{*}{$\begin{array}{l}\text { Sala de atividades } \\
\text { coletivas }\end{array}$} & Serviços gerais & \\
\hline & & $\begin{array}{l}\text { Técnico com formação em } \\
\text { Direito, pedagogia, } \\
\text { sociologia, antropologia ou } \\
\text { Terapia Ocupacional }\end{array}$ & \\
\hline
\end{tabular}

Fonte: BRASIL (2011), adaptada pela autora (2018)

Ao comparar a Tabela 1 do Ministério da Saúde com as exigências do Ministérios do Desenvolvimento Social (Quadro 1), percebe-se que há carência de espaços físicos para a realização das ações. Como contribuição compatibilizou-se a tabela e o quadro a fim de sistematizar uma que possibilite a efetivação dos objetivos (ver Tabela 2). Os ambientes mínimos foram estabelecidos conforme as orientações técnicas do Ministério da Saúde e o pré-dimensionamento baseado em Littlefield (2004).

Tabela 2 - Compatibilização das Tabelas 1 e Quadro 1

\begin{tabular}{|c|c|c|}
\hline \multirow{2}{*}{ Setores } & Ambientes & $\begin{array}{c}\text { Área } \\
\text { Mín. }\end{array}$ \\
\hline \multirow{4}{*}{ Serviço } & Abrigo para resíduos sólidos & $4 \mathrm{~m}^{2}$ \\
\cline { 2 - 3 } & Almoxarifado & $3 \mathrm{~m}^{2}$ \\
\cline { 2 - 3 } & Banheiro funcionários & $12 \mathrm{~m}^{2}$ \\
\cline { 2 - 3 } & Copa funcionários & $16 \mathrm{~m}^{2}$ \\
\cline { 2 - 3 } & Embarque e desembarque de ambulância & $21 \mathrm{~m}^{2}$ \\
\cline { 2 - 3 } & Estacionamento *dimensão para 1 vaga & $13 \mathrm{~m}^{2}$ \\
\cline { 2 - 3 } & Guarita & $10,56 \mathrm{~m}^{2}$ \\
\cline { 2 - 3 } & Garagem & $14,5 \mathrm{~m}^{2}$ \\
\hline
\end{tabular}




\begin{tabular}{|c|c|c|}
\hline & Recepção & $18 m^{2}$ \\
\hline & Vestuário & $16,30 \mathrm{~m}^{2}$ \\
\hline \multirow{4}{*}{ Social } & Quadra poliesportiva & $432 m^{2}$ \\
\hline & Área externa de convivência & $24 m^{2}$ \\
\hline & Sala de Jogos & $40 m^{2}$ \\
\hline & Sala de TV & $15 m^{2}$ \\
\hline \multirow{5}{*}{ Ensino } & Ateliê & $50 m^{2}$ \\
\hline & Biblioteca & $303,6 \mathrm{~m}^{2}$ \\
\hline & Sala de atividades coletivas & $56 m^{2}$ \\
\hline & Sala de aula & $56 m^{2}$ \\
\hline & Sala de Inclusão Digital & $28,4 m^{2}$ \\
\hline \multirow{8}{*}{ Acolhimento } & Banheiros individuais & $4,8 m^{2}$ \\
\hline & Quarto individual & $13 m^{2}$ \\
\hline & Quarto coletivo (máx. 4 pessoas) & $18 m^{2}$ \\
\hline & Refeitório + cozinha & $120 m^{2}$ \\
\hline & Sala de acolhimento & $12,95 \mathrm{~m}^{2}$ \\
\hline & Sala de atendimento & $12,95 \mathrm{~m}^{2}$ \\
\hline & Sala de atendimento médico & $16 \mathrm{~m}^{2}$ \\
\hline & Lavanderia & $7 m^{2}$ \\
\hline \multirow{4}{*}{ Administrativo } & Sala da coordenação & $9 m^{2}$ \\
\hline & Sala de reunião & $17,82 \mathrm{~m}^{2}$ \\
\hline & Sala da administração & $9 m^{2}$ \\
\hline & Sala de arquivo & $9 m^{2}$ \\
\hline
\end{tabular}

Fonte: Elaborado pela autora (2018) com base nas orientações do Ministério da Saúde e Ministério do Desenvolvimento Social

Quadro 3: Critérios para o Diagnóstico Socioterritorial

\begin{tabular}{|c|c|c|}
\hline Critérios & Avaliação & \\
\hline $\begin{array}{l}\text { Incidência de } \\
\text { pessoas em } \\
\text { situação de } \\
\text { rua }\end{array}$ & $\begin{array}{l}\text { Observar o fluxo de pessoas de rua ao entorno do } \\
\qquad \text { local de análise; } \\
\text { Em conversa com a comunidade e com os centros } \\
\text { de assistência social, saber se há um elevado fluxo e } \\
\text { concentração de moradores de rua na cidade. }\end{array}$ & $\begin{array}{l}\text { Alta } \\
\text { Média } \\
\text { Baixa }\end{array}$ \\
\hline $\begin{array}{l}\text { Rede de } \\
\text { articulação } \\
\text { de serviços } \\
\text { próximos }\end{array}$ & $\begin{array}{c}\text { Observar se a rede de serviços que apoiam a } \\
\text { assistência social está nas proximidades e possibilita a } \\
\text { articulação dos mesmos; } \\
\text { Mapear serviços assistenciais }\end{array}$ & $\begin{array}{c}\text { Possibilita/Possibilita } \\
\text { parcialmente/Não } \\
\text { possibilita } \\
\text { CRAS } \\
\text { CREAS } \\
\text { CENTRO POP } \\
\text { CAPS } \\
\text { UBS } \\
\text { Abordagem Social }\end{array}$ \\
\hline \multirow{4}{*}{$\begin{array}{l}\text { Local de fácil } \\
\text { acesso }\end{array}$} & \multicolumn{2}{|c|}{ Observar se o local é de fácil acesso quanto: } \\
\hline & - visibilidade/ldentificação; & Alta/Média/Baixa \\
\hline & - perto dos pontos de chegada dos moradores de rua; & Próximo/Não próximo \\
\hline & - se há transporte público nas proximidades. & Sim/Não \\
\hline
\end{tabular}

Fonte: BRASIL (2011), adaptado pela autora (2018) 
Todos os itens da Tabela 2 serão adotados como critérios de qualidade para avaliação nos estudos de caso.

Ainda com base nas orientações do Ministério do Desenvolvimento Social, o local onde está ou será inserida a Unidade de Acolhimento deverá ser analisado através da aplicação dos critérios expostos no Quadro 3, a fim de gerar um Diagnóstico Socioterritorial que reunirá informações sobre a área e qualificará sua viabilidade.

\subsection{Humanização e Psicologia Ambiental}

Ao pensar a arquitetura nos espaços assistenciais de saúde deve-se ter a consciência de que "é uma arquitetura feita para o ser humano em sua condição de maior sensibilidade" (CIACO, 2010, p. 27). Dessa forma, estudar a Unidade de Acolhimento como um espaço de saúde que as pessoas em situação de rua buscam para melhoria de suas vidas, tende a correlação dos princípios da Humanização (domesticidade, privacidade, conforto ambiental e visual) e dos conceitos da Psicologia Ambiental, como a preocupação com a percepção e sentimento do usuário no ambiente, conforme norteiam Ciaco (2010) e Kowaltowski (1989). Nesse sentido, o Ministério da Saúde já orienta no Manual sobre o cuidado à saúde junto à população em situação de rua: "a produção de uma rede de cuidado traz consigo a proposta da humanização das ações e serviços de saúde" (BRASIL, 2012, p. 40).

No enfoque da Humanização, Kowaltowski (1989) afirma que ela atua como ferramenta para concepção de espaços saudáveis voltados para o ser humano, onde a preocupação com criação de laços com o ambiente e a sensação de conforto seja estimulada nos usuários.

\section{Quadro 4-Aspectos Humanizadores}

\begin{tabular}{|c|c|}
\hline Fator analisado & Avaliação \\
\hline Valorização do usuário & Conforto ambiental; organização; silêncio; acolhimento. \\
\hline Sob a ótica da legislação & $\begin{array}{c}\text { Orientações do Ministério da Saúde e do Ministério do } \\
\text { Desenvolvimento Social; Política Nacional para População em } \\
\text { Situação de Rua; Tipificação Nacional dos Serviços } \\
\text { Assistenciais. }\end{array}$ \\
\hline $\begin{array}{l}\text { Valorização dos } \\
\text { profissionais da saúde }\end{array}$ & $\begin{array}{c}\text { Ambiente privativo para os funcionários; qualidade; conforto } \\
\text { ambiental. }\end{array}$ \\
\hline Adequação ao local & Insolação; Acessibilidade; Infraestrutura; Estudo do entorno. \\
\hline $\begin{array}{l}\text { Estudo do projeto deve ser } \\
\text { funcional e técnico }\end{array}$ & $\begin{array}{l}\text { Flexibilidade; previsão de expansão; percursos; fluxos } \\
\text { segregados. }\end{array}$ \\
\hline $\begin{array}{l}\text { Racionalização: circulações } \\
\text { e usos }\end{array}$ & Agrupamento dos usos; circulação restrita e segregada. \\
\hline Flexibilidade dos ambientes & Adaptações; ampliação; planta livre; divisórias móveis. \\
\hline Conforto Ambiental & $\begin{array}{l}\text { Conforto Térmico; ventilação natural; conforto visual; } \\
\text { iluminação natural; uso das cores. }\end{array}$ \\
\hline Presença do verde & $\begin{array}{l}\text { Presença de jardins externos/internos; cuidados paisagísticos; } \\
\text { utilização da água. }\end{array}$ \\
\hline Relação interior $x$ exterior & Aberturas: comunicação com a área externa. \\
\hline
\end{tabular}

Fonte: CIACO (2010), adaptada pela autora (2018)

Assim, a psicologia ambiental, segundo Aragonés e Amérigo (1998), traz a importância das trocas de experiências na relação pessoa-ambiente e analisa 
como essa interação atua no funcionamento psicológico do usuário frente a um determinado espaço.

Logo, Ciaco (2010) orienta que as ações dentro de um espaço de saúde devem ser aliadas aos fatores como: implantação adequada; iluminação; ventilação; mobiliário; flexibilidade dos ambientes; utilização de cores; som e água, e racionalização interior x exterior, como podem ser vistos no Quadro 4.

Concomitantemente aos requisitos básicos de Ciaco (2010), Kowaltowski (1989) revela como os princípios arquitetônicos podem influenciar nas sensações dos usuários quando inseridos dentro de um espaço mais humano (ver Quadro 5).

Quadro 5 - Princípios Arquitetônicos na Humanização

\begin{tabular}{|c|c|}
\hline Princípios Arquitetônicos & Sensações \\
\hline Estética & Fornece estímulo/conforto visual \\
\hline Natureza & $\begin{array}{c}\text { Satisfação visual; } \\
\text { Porte reduzido das construções }\end{array}$ \\
& $\begin{array}{c}\text { Sentimento de ambiente saudável. } \\
\text { Maximização do funcionamento de grupos; } \\
\text { Sentimento de territorialidade; } \\
\text { Locomoção horizontal. }\end{array}$ \\
\hline Domesticidade & Tradição, privacidade e família; \\
& Ambiente de moradia tradicional; \\
& Sentimentos territoriais. \\
\hline
\end{tabular}

Fonte: KOWALTOWSKI (1989), adaptada pela autora (2018)

A domesticidade, como um dos princípios tratados por Kowaltowski (1989), resgata os sentimentos de territorialidade, privacidade e tradição familiar também mencionados por Aragonés e Amérigo (1998) no campo da psicologia ambiental.

Reitera-se "Os ingredientes de territorialidade, segurança e espaço pessoal, implicados pelos princípios da domesticidade, têm conotações psicológicas pertencentes ao sentimento de posse, simbolizados pela casa" (KOWALTOWSKI, 1989, p. 131). Nessa concepção, a aplicação desse princípio torna-se imprescindível para estimular a apropriação do espaço pelo usuário e assim causar a sensação de pertencimento ao lugar.

Outro ponto comum estudado pela humanização e pela psicologia ambiental, citados por Kowaltowski (1989) e por Aragonés e Amérigo (1998), é a importância do porte reduzido das edificações para valorização da locomoção horizontal, da comunicação social e da orientação espacial e como isso está diretamente relacionado à satisfação e bem-estar do usuário frente ao ambiente exposto.

Nesse sentido, Aragonés e Amérigo (1998) no âmbito da psicologia ambiental, colocam a pessoa como foco central e estudam em seu contexto habitual a relação social-ambiental sobre seu psicológico e junto aos princípios da humanização elencam os instrumentos essenciais para a produção de espaços vividos pelo homem a fim de lhe garantir conforto e experiências efetivas sem esforços e sem estresse.

Portanto, torna-se necessário triangular a humanização, a psicologia ambiental e os espaços assistenciais no processo de concepção de uma 
Unidade de Acolhimento para reestabelecer a saúde mental, resgatar a qualidade de vida e reconstruir os vínculos rompidos para reinserir o morador de rua na sociedade.

\subsection{Desenho Universal}

O conceito de Desenho Universal por Cambiaghi (2007) busca a consolidação dos Direitos Humanos através da criação de ambientes que possam ser usados pelo máximo número de pessoas de forma autônoma, segura, sem esforços desnecessários e com sentimento de bem-estar. Assim, não se trata apenas de normas técnicas, e sim questões interdisciplinares entre humanização, psicologia e conforto ambiental.

Por conseguinte, a preocupação com a relação pessoa-ambiente no cenário do Desenho Universal é considerada, por Cambiaghi (2007) parte integrante do processo de criação de espaços acessíveis e autônomos, funcionais e de qualidade.

Dessa forma, a aplicação do Desenho Universal por um olhar humanizado fazse necessária no âmbito da Unidade de Acolhimento, sendo, segundo Cambiaghi (2007), inerente ao projeto arquitetônico ponderar sobre a heterogeneidade das deficiências e necessidades humanas.

Para os estudos de caso foram utilizadas as Planilhas de Avaliação (Figura 1) elaboradas por Dischinger, Ely e Piardi (2012) no Programa de Acessibilidade às Pessoas com Deficiência ou Mobilidade Reduzida nas Edificações de Uso Público do Ministério de Santa Catarina.

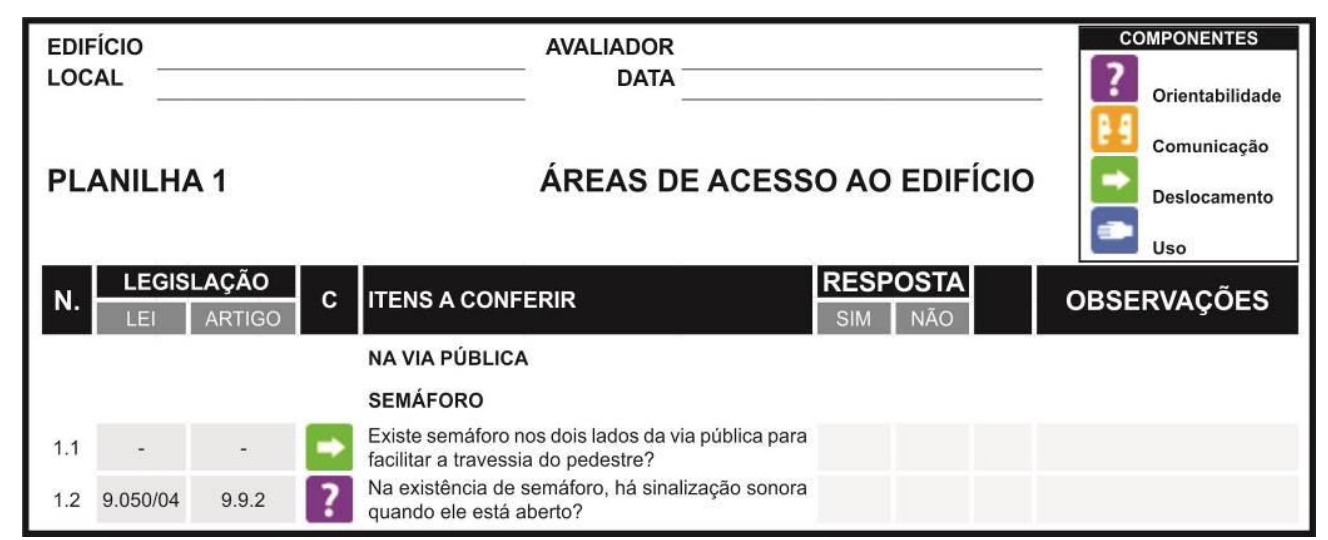

Figura 1 - Exemplo da configuração da Planilha de Avaliação usado no estudo de caso -

Fonte: DISCHINGER; ELY; PIARDI (2012)

Nessa perspectiva, Dischinger, Ely e Piardi (2012) afirmam que os aspectos da acessibilidade espacial devem ser cumpridos em sua totalidade, porque "basta o não cumprimento de um deles para que todos os demais sejam comprometidos".

\section{METODOLOGIA}

\subsection{Procedimento metodológico para o estudo de caso}

A seleção de três procedimentos metodológicos (entrevista, walkthrough e mapa comportamental) para a análise do Estudo de Caso possibilita a 
triangulação dos métodos, o conhecimento dos aspectos positivos e das problemáticas existentes nas instituições, as necessidades para o funcionamento das ações e a geração das diretrizes projetuais a partir dos dados coletados.

Optou-se por uma entrevista semiestruturada com perguntas abertas, para o walkthrough foram elaborados checklists com critérios para avaliar as edificações quanto a estrutura física e espacial e o mapa comportamental como instrumento para registrar as atividades e os comportamentos dos usuários nos espaços.

Para tal, os critérios de avaliação fundamentaram-se nas pesquisas realizadas sobre a Humanização, nos estudos de Ciaco (2010) e Kowaltowski (1989), sobre a Psicologia Ambiental de Aragonés e Amérigo (1998), sobre as orientações pelo Ministério da Saúde quanto aos ambientes para atender as ações e sobre a aplicação do Desenho Universal por Cambiaghi (2007).

\subsection{Estudo de caso}

Tomando-se por base a exigência da articulação entre os serviços sociais, pela Tipificação Nacional dos Serviços Socioassistenciais, optou-se como objeto de estudo duas instituições do município de Tubarão/SC. Sendo, o Centro POP (Figura 2), por ser um serviço especializado às pessoas em situação de rua e o Albergue Noturno Pousada da Paz (Figura 3), por ser referência de Unidade de Acolhimento no Estado de Santa Catarina.

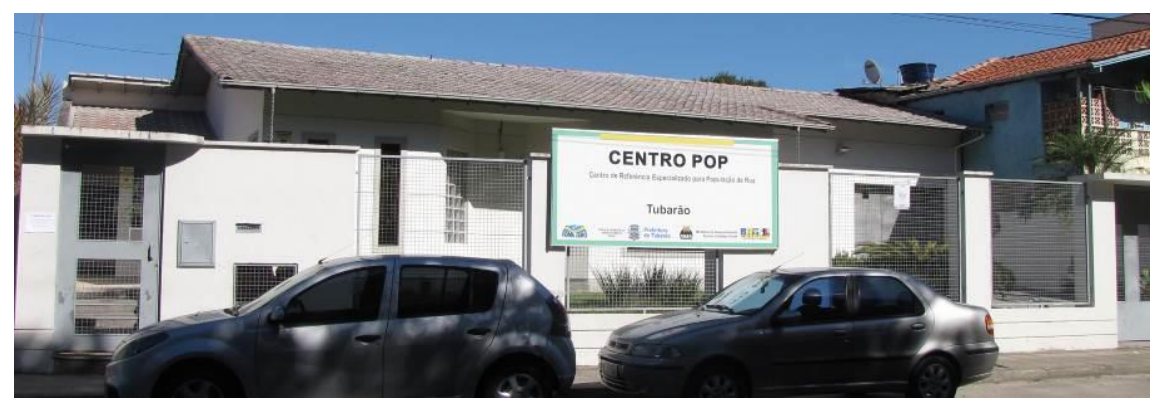

Figura 2 - Centro POP - Tubarão/SC -

Fonte: Acervo da autora (2018)

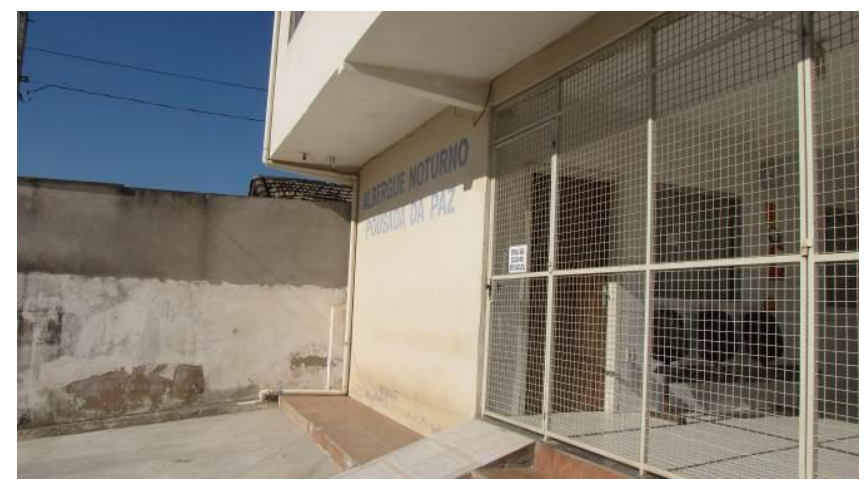

Figura 3 - Albergue Noturno Pousada da Paz - Tubarão/SC Fonte: Acervo da autora (2018) 


\subsection{Resultados e Discussões}

Em síntese, o entrelaçamento dos dados coletados durante o estudo de caso através dos checklists revelou uma precariedade nos espaços ofertados às pessoas em situação de rua quanto a presença, quantidade e qualidade. A assistente social do Centro POP reforça essa situação com a sua fala, durante a entrevista, de que "Santa Catarina ainda tá muito mal preparada para atender a população de rua".

Ao realizar a síntese comparativa entre as instituições (ver Quadro 8), percebeu-se que ambas mostraram falha na qualidade, e inclusive ausência de espaços para a realização das atividades e das ações, sendo que as dimensões dos ambientes se encontraram fora das normas do Ministério da Saúde.

\section{Quadro 8 - Síntese Comparativa}

\begin{tabular}{|c|c|c|c|}
\hline & CENTRO POP & \multicolumn{2}{|c|}{ Albergue Noturno Pousada da Paz } \\
\hline \multirow{5}{*}{ Diagnóstico Socioterritorial } & Articulação de serviços socioassistenciais & Articulação de serviços socioassistenciais & \\
\hline & Visibilidade & \begin{tabular}{|l|} 
Visibilidade \\
\end{tabular} & \\
\hline & Fácil acesso & Fácil acesso & \\
\hline & Próximo de vias principais & Próximo de vias principais & \\
\hline & Inserção em bairro residencial & Inserção em bairro residencial & \\
\hline \multirow{7}{*}{ Parâmetros Construtivos } & Segurança & Segurança & \\
\hline & Estanqueidade & Estanqueidade & \\
\hline & Conforto Acústico & Conforto Acústico & \\
\hline & Conforto Térmico & Conforto Térmico & \\
\hline & Conforto Luminoso & Conforto Luminoso & \\
\hline & Conforto Visual & Conforto Visual & \\
\hline & Adaptação ao uso & Adaptação ao uso & \\
\hline \multicolumn{4}{|l|}{ Ambientes Mínimos } \\
\hline \multirow{12}{*}{ Humanização } & Valorização do utente & Valorização do utente & \\
\hline & Legislação & Legislação & \\
\hline & Valorização dos profissionais & Valorização dos profissionais & \\
\hline & Adequação ao local & Adequação ao local & \\
\hline & Projeto funcional & Projeto funcional & \\
\hline & Racionalização das circulações & Racionalização das circulações & \\
\hline & Agrupamento de usos afins & Agrupamento de usos afins & \\
\hline & Flexibilidade dos ambientes & Flexibilidade dos ambientes & \\
\hline & Conforto Ambiental & Conforto Ambiental & \\
\hline & Presença de verde & Presença de verde & \\
\hline & Relação interior $\mathrm{x}$ exterior & Relação interior $\mathrm{x}$ exterior & \\
\hline & Humanização dos espaços & Humanização dos espaços & \\
\hline Desenho Universal & & & \\
\hline
\end{tabular}

No que concerne à circulação, há conflitos de usos, onde um único espaço é usado para diversas funções. O uso do verde mostrou-se ausente, bem como áreas de convivência externa, o que impossibilita qualquer interação com o entorno. Os itens analisados dentro dos parâmetros do Desenho Universal mostraram-se ausentes em sua maior parte, e quando presentes atendem de maneira ineficaz.

\section{CONSIDERAÇÕES FINAIS}

Por conseguinte, a triangulação dos dados coletados durante a metodologia possibilitou o mapeamento das atividades, do comportamento dos usuários, fez-se compreender o funcionamento de uma Unidade de Acolhimento na prática e dessa forma, conhecer as carências de ações e espaços. 
Com base no exposto e nas deficiências encontradas, viu-se a necessidade de propor diretrizes projetuais (ver Quadro 9) para uma Unidade de Acolhimento que atenda aos requisitos mínimos de forma funcional e com qualidade.

\section{Quadro 9 - Diretrizes Projetuais}

\begin{tabular}{|c|c|}
\hline \multicolumn{2}{|r|}{ Diretrizes Projetuais } \\
\hline $\begin{array}{l}\text { Diagnóstico } \\
\text { Socioterritorial }\end{array}$ & $\begin{array}{l}\text { Inserção em Zona Residencial; } \\
\text { Proximidade aos pontos de maior fluxo de moradores de rua; } \\
\text { Promoção das articulações dos serviços assistenciais; }\end{array}$ \\
\hline $\begin{array}{l}\text { Parâmetros } \\
\text { Construtivos }\end{array}$ & $\begin{array}{l}\text { lluminação e ventilação natural } \rightarrow \text { aberturas (conforto ambiental - } \\
\text { condicionamento passivo); } \\
\text { Planta livres } \rightarrow \text { flexibilidade; }\end{array}$ \\
\hline Ambientes & $\begin{array}{l}\text { Atender aos ambientes mínimos exigidos pelo Ministério da saúde e pelo } \\
\text { Ministério do Desenvolvimento Social. }\end{array}$ \\
\hline Humanização & $\begin{array}{c}\text { Plantas livres } \rightarrow \text { flexibilidade, adaptação de uso e alteração de layout; } \\
\text { Agrupamento de usos } \rightarrow \text { fluxos segregados, racionalização de circulações; } \\
\text { Aberturas } \rightarrow \text { iluminação e ventilação natural, relação interior x exterior } \\
\text { (conforto ambiental); } \\
\text { Valorização dos funcionários } \rightarrow \text { ambiente privativo; } \\
\text { Paisagismo } \rightarrow \text { conforto visual, espaços de convivência relacionados à } \\
\text { natureza para auxiliar na saúde mental; }\end{array}$ \\
\hline $\begin{array}{l}\text { Desenho } \\
\text { Universal }\end{array}$ & $\begin{array}{c}\text { Uso autônomo; } \\
\text { Agrupamento de usos } \rightarrow \text { evita grandes descolamentos; } \\
\text { Ambientes acessíveis } \rightarrow \text { NBR 9050; } \\
\text { Baixo esforço físico/fácil acesso } \rightarrow \text { evitar desníveis. }\end{array}$ \\
\hline
\end{tabular}

Dessa forma, todo o estudo aqui apresentado caminhou para subsidiar uma base de diretrizes para o lançamento de um programa de necessidades que cumpra os requisitos do Ministério da Saúde, do Ministério do Desenvolvimento Social e sejam atrelados aos princípios da humanização para promoção de um ambiente mais saudável e humano dentro de centros assistenciais de saúde.

\section{REFERÊNCIAS}

ARAGONÉS, J. I.; AMÉRIGO, M. Psicología Ambiental. Madrid: Pirámide, 1998. $483 \mathrm{p}$.

BRASIL. MINISTÉRIO DO DESENVOLVIMENTO SOCIAL. Orientaçōes

Técnicas: Centro de Referência Especializado para População em Situação de Rua - Centro Pop. Brasília: Brasil Ltda, 2011 . 3 v. Disponível em: <http://www.mds.gov.br/webarquivos/publicacao/assistencia_social/Caderno s/orientacoes_centro_pop.pdf>. Acesso em: 12 fev. 2018.

. MINISTÉRIO DA SAÚDE. SECRETARIA DE ATENÇÃO À SAÚDE. Manual sobre o cuidado à saúde junto à população em situação de rua. Brasília: Ms Os, 2012.100 p. (A). Disponível em: <http://189.28.128.100/dab/docs/publicacoes/geral/manual_cuidado_populal cao_rua.pdf>. Acesso em: 09 maio 2018.

CAMBIAGHI, S. Desenho Universal: Métodos e técnicas para Arquitetos e Urbanistas. São Paulo: Senac, 2007. 
CIACO, R. J. A. S. A Arquitetura no Processo de Humanização dos Ambientes Hospitalares. 2010. 150 f. Dissertação (Mestrado) - Curso de Arquitetura e Urbanismo, Escola de Engenharia de São Carlos, Universidade de São Paulo, São Carlos, 2010. Disponível em:

<http://www.teses.usp.br/teses/disponiveis/18/18141/tde-05012011155939/en.php>. Acesso em: 15 mar. 2018.

DISCHINGER, M.; ELY, V. H. M. B.; PIARDI, S. M. D. G. Promovendo acessibilidade espacial nos edifícios públicos: Programa de Acessibilidade às Pessoas com Deiciência ou Mobilidade Reduzida nas Ediicações de Uso Público.

Florianópolis: MPSC, 2012.161 p. Disponível em:

<http://www.mpam.mp.br/attachments/article/5533/manual_acessibilidade_c ompactado.pdf>. Acesso em: 07 mar. 2018

ESQUINCA, M. M. M. Os deslocamentos territoriais dos adultos moradores de rua nos bairros Sé e República. 2013. 254 f. Dissertação (Mestrado) - Curso de Arquitetura e Urbanismo, Universidade de São Paulo, São Paulo, 2013.

Disponível em: <http://www.teses.usp.br/teses/disponiveis/16/16133/tde15012014-141047/pt-br.php>. Acesso em: 26 mar. 2018.

LOSCHIAVO, M. C. Arquitetura, os moradores de rua e a transfiguração de nossa sociedade. 2005. Disponível em:

<https://www.ufrgs.br/propar/publicacoes/ARQtextos/PDFs_revista_7/7_Maria Cecilia Loschiavo.pdf>. Acesso em: 9 jan. 2018.

KOWALTOWSKI, D. C. C. K. Arquitetura e Humanização: Projeto. Projeto, v.126, p. 129-132, out. 1989. Disponível em: <http://www.dkowaltowski.net/675.pdf>. Acesso em: 04 mar. 2018.

LITTLEFIELD, D Manual do Arquiteto: Planejamento, Dimensionamento e Projeto. 3. ed. Porto Alegre: Bookman, 2011. 767 p. Tradução de: Alexandre Salvaterra. 